\title{
An Image Based Mathematical Model for the Propagation of Fan Noise in a Plenum with Large Side Openings
}

\author{
Michael J. Panza \\ Gannon University, 109 University Square, Erie, PA 16541, USA \\ Correspondence should be addressed to Michael J. Panza; panza@gannon.edu
}

Received 6 April 2015; Accepted 15 September 2015

Academic Editor: Gurvinder S. Virk

Copyright (C) 2015 Michael J. Panza. This is an open access article distributed under the Creative Commons Attribution License, which permits unrestricted use, distribution, and reproduction in any medium, provided the original work is properly cited.

\begin{abstract}
This paper presents another application of an images group model for a special enclosure geometry and source orientation. A previous work outlined the concept via application to a special tight-fitting enclosure. Application of the concept to a fan plenum requires different mathematical descriptions for the image groups. This paper describes the sound reverberation inside a sound enclosure with mostly open sides where the primary noise sources are the air inlets and exhausts of axial type fans located at the top of the enclosure, the sound transmission through the air inlet openings, and the radiation to wayside positions. The main reverberation between the floor and ceiling is determined with an image based mathematical model. The model considers how the main reverberant part image group is amplified by its images from two parallel bulkheads and any side wall frame members. The method of images approach allows the hard surfaces of an untreated plenum to be represented by perfectly reflecting surfaces with zero sound absorption coefficients, thus not requiring any estimate or measurement for these surfaces. Numerical results show excellent comparison to experimental results for an actual plenum. The image model is also shown to be significantly more accurate than the standard large room diffuse field reverberant model.
\end{abstract}

\section{Introduction}

The propagation of fan noise in a plenum with large side openings requires an accurate method for modeling the reverberation in an acoustical enclosure where air openings are present. Kim and Ih [1] applied a classic multimodal model to a three-dimensional enclosure containing reflecting/absorptive surfaces with complex impedance. The effective absorption of inlet and exhaust openings was not considered. Thus, their model should be applied to a plenum with openings of small area compared to the overall plenum. Osman [2] applied a large room diffuse field reverberant model (Sabine model) to an engine enclosure with openings by assigning an absorption coefficient value of one to the open areas as part of the contribution to the total enclosure Sabines. Forouharmajd and Nassiri [3] applied a large room diffuse field reverberant model (Sabine model) to a short plenum with small source and openings on opposite corners. Thus, their models also could be applied to a fan plenum with openings of small area compared to the overall plenum. Several studies focused on the sound field along corridors or long enclosures using methods other than the large room diffuse field model. Davies [4] and Chu and Tang [5] used a modal expansion across the corridor or enclosure side walls with a study of the sound level along the corridor or long enclosure. Yamamoto [6], Redmore [7], and Kang [8] used image expansions across the corridor or enclosure side walls with a study of the sound level along the corridor or along enclosure. Bies and Hansen [9] provide a section for long enclosures and summarize formulas that can be used to approximate the sound level in them. None of these studies focused on the near field behavior that is required for a fan plenum with large open sides.

This paper describes the sound reverberation inside a prismatic sound enclosure with mostly open sides where the noise sources are the air inlets of axial type fans located at the top of the enclosure, the sound transmission through the air inlet openings, and the radiation to wayside positions. The enclosure dimensions make it essentially a very short tunnel. It also includes the radiation from the exhaust end of the fans to the wayside. This sound power from the fan inlet is considered equal to the sound power from the fan exhaust, 
TABLE 1: Basic concept and novelties for group images method.

\begin{tabular}{lll}
\hline Steps in the group images method & Tight-fitting enclosure in reference [10] & Fan plenum enclosure in this paper \\
\hline $\begin{array}{l}\text { Define the source model relative to } \\
\text { enclosure }\end{array}$ & $\begin{array}{l}\text { A machine surface comprising one side of } \\
\text { enclosure modeled as uniformly and } \\
\text { randomly distributed over the machine } \\
\text { surface due to multimodal machine } \\
\text { surface vibration }\end{array}$ & $\begin{array}{l}\text { Axial fan(s) modeled as point source with } \\
\text { directivity located at the ceiling area of } \\
\text { the plenum }\end{array}$ \\
\hline $\begin{array}{l}\text { Select the main reverberation group as } \\
\text { that between the closest set of parallel } \\
\text { enclosure surfaces }\end{array}$ & $\begin{array}{l}\text { The reverberation between the machine } \\
\text { surface and its opposite wall located close } \\
\text { to it with an integration over the machine } \\
\text { source surface }\end{array}$ & $\begin{array}{l}\text { The reverberation between the floor and } \\
\text { ceiling (comprising the fans) from the } \\
\text { point source fan(s) }\end{array}$ \\
\hline $\begin{array}{l}\text { Select the second group as the images of } \\
\text { the first group due to the other one or two } \\
\text { sets of parallel enclosure surfaces }\end{array}$ & $\begin{array}{l}\text { Images projected by the area source along } \\
\text { the ceiling-floor and side wall-side wall } \\
\text { sets; this results in single summations }\end{array}$ & $\begin{array}{l}\text { Images projected by the point source } \\
\text { along the bulkhead-bulkhead set as well } \\
\text { as the four quadrants comprising } \\
\text { floor-ceiling, bulkhead-bulkhead images; } \\
\text { this results in double summations }\end{array}$ \\
$\begin{array}{l}\text { Use of a factor } F \text { for including the group } \\
\text { of highest order or extra surfaces images } \\
\text { that occur }\end{array}$ & $\begin{array}{l}\text { Images produced from the combination } \\
\text { of the main group and second group, } \\
\text { which lie in four quadrants }\end{array}$ & $\begin{array}{l}\text { Images produced from solid portion of } \\
\text { side wall areas containing the large } \\
\text { openings and due to the main group and } \\
\text { second group sets }\end{array}$ \\
$\begin{array}{l}\text { Model for the directivity of the direct } \\
\text { path from source to enclosure surface } \\
\text { that would serve as the radiation area to } \\
\text { external space }\end{array}$ & $\begin{array}{l}\text { The directivity is inherent in the } \\
\text { Hohenwarter [11] radiation model from } \\
\text { an area source }\end{array}$ & $\begin{array}{l}\text { The directivity is modeled using the } \\
\text { analysis from Morse and Ingard [12] by } \\
\text { considering the fan area as random } \\
\text { radiation with directivity relative to a } \\
\text { point source }\end{array}$
\end{tabular}

which is typical for axial type fans. The model is applicable to a broad range of frequencies associated with the radiator fan noise.

This paper represents another important application of the group images model concept area to a special type of enclosure for predicting the internal intensity incident on the inside of an enclosure wall that would serve as the radiation area to the enclosure external space. This approach for another special type of enclosure was presented in a previous study by the author [10]. Special means the enclosure geometry and source orientation are generally not well suited for predicting the reverberation with a large diffuse room Sabine type of enclosure. The previous work by the author [10] outlined the basic group images model concept, applied it to a close-fitting enclosure, and demonstrated its differences from a large diffuse room Sabine type of enclosure. Both a tightfitting enclosure with one nearby wall being an area noise source and an open-sided fan plenum enclosure with a point source have the special geometries and source orientations that do not generally fall into the class of large diffuse room Sabine types. The application of the group images model represents a unique approach for how to select the main image group relative to specific type of noise source. This paper includes a similar basic concept of the group images model presented in the tight-fitting paper, but a unique way of defining and mathematically describing the groups for the special type of fan plenum is considered here. In addition to comparison with the large diffuse room Sabine type result, the application of the group image model is verified experimentally here.

A summary of the group images model concept and how it is uniquely applied for the two types of special enclosures defined in the previous and present studies is given in Table 1. One key factor for both special cases, which is the underlying goal of the method, is that all hard wall surfaces are modeled with a value of zero sound absorption coefficient (i.e., perfectly reflecting). This factor means that the typical hard wall enclosures comprising the vast majority of enclosures do not require an initial test or a rough (usually inaccurate) approximation for an enclosure's reverberation properties prior to estimating the effect of adding sound absorption to internal reverberation.

As indicated by Table 1, the basic concept of the group images method underlies both special enclosure examples but the mathematical descriptions can be different due to the unique ways for which the steps in the method are defined relative to the specific enclosure case. Novel mathematical descriptions relative to the special fan plenum image groups are required and presented here. An additional step included in this paper that was not included in the previous paper is the calculation of the sound pressure level at a location external to the enclosure and verification of the model with experimental results. The fan plenum enclosure case was more amenable for experiment due the large side opening for radiation not requiring a separate measurement of wall sound transmission loss and the access to a large isolated locomotive engine radiator cab that fit well into this special case.

The noise source to the enclosure is the sound power from the fan inlets. The enclosure is defined as the region from plenum floor to the fans, heat exchangers combination defining the enclosure ceiling, the two side walls with mostly open area, and solid left and right bulkheads. The main reverberation is between the floor and ceiling, both considered as purely reflective surfaces (the combination of a rotating fan 
and the heat exchanger essentially blocks all of the noise from passing through it and thus can be considered as a perfectly reflecting ceiling). For this main reverberation, one-half of the total fan sound power as measured by AMCA procedures is considered to travel to each of the two plenum side walls. The main reverberant part described above is amplified by considering its images from the two bulkheads' reflections, its images from combined bulkheads, floor/ceiling reflections, and a factor accounting for possible multiple reflections from the small amount of acoustically hard surfaces in the side wall frame members.

As previously presented by Panza [10] for a tightfitting enclosure, the method of images approach for an unconventional tight-fitting enclosure is applied here to an untreated plenum containing no sound absorption with hard surfaces represented by perfectly reflecting surfaces with zero sound absorption coefficient. It then allows supplier measured sound absorption coefficient value to be used for an acoustically treated plenum. Thus, as is not the case with the standard large room reverberation model, the untreated internal surface condition does not have to be measured or estimated for an actual plenum. The sound absorption coefficient value $\alpha$ for all hard surfaces is set equal to zero. This is important because the theoretical sound absorption coefficient $\alpha$ of acoustically hard steel or fiberglass surfaces that comprise the plenum interior can range from 0.001 to 0.05 . Additionally, the large room reverberation model gives a singularity as $\alpha$ approach 0 due to a reverberant field contribution inversely proportional to $\alpha$.

The reverberant sound intensity incident perpendicular to plenum side walls determines the power flow through the openings and is accounted for in all image radiations towards the side walls. The direct field directivity of the fan is included for the direct sound from fan to side wall and the fan directivity is included for fan exhaust radiation to the wayside at an angle of 90 degrees.

Radiation from the plenum side wall opening to wayside positions is computed with the Hohenwarter [11] formula which models a rectangular plane surface as $I_{\text {normal }} \cos ^{2}(\theta)$ and represents an accurate compromise between monopole-like and dipole-like radiation.

\section{Internal Sound Field Model}

Figures 1-3 give a layout of the coordinate system and the image groups.

Figure 1 is a 3-dimensional view of the internal plenum volume identifying the surfaces that may contribute to increased internal sound absorption. The main reverberation is along the $z$-axis between the floor and the ceiling. $H_{o}$ is the centroid of open area and for several different side openings is determined with the standard method for centroids. $A_{o}$ and $A_{s}$ are the total amount of air inlet and solid areas, respectively.

Figure 2 is an elevation view of the $x-z$ plane showing the fan, the direct radiation to the air inlet openings (centroid located Ho from the floor), and the multiple floor and ceiling images.

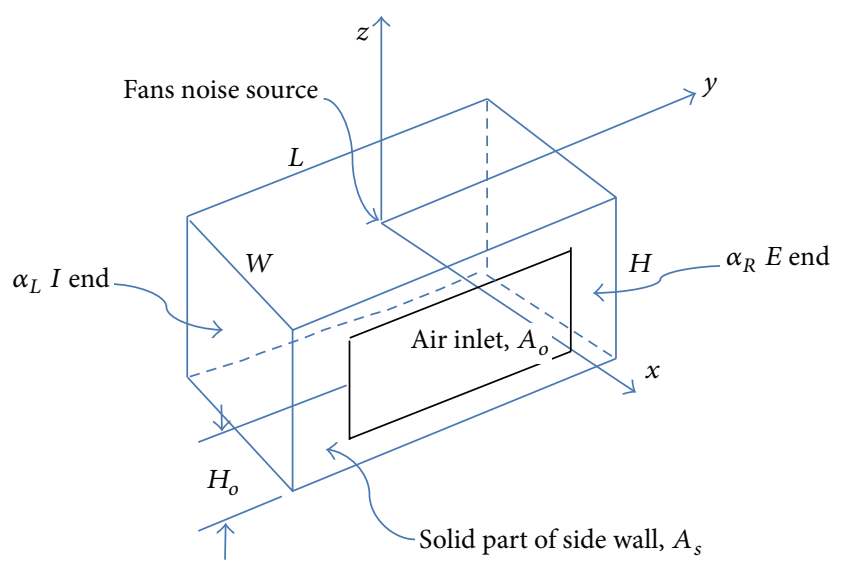

FIGURE 1: Primary reverberation occurs in the region between the plenum floor and ceiling defined by the fans and heat exchangers combination. Secondary reverberation occurs between the two end walls and between the solid portions of the two-side walls.

Figure 3 is an elevation view of the $y-z$ plane showing the first image groups for the two plenum bulkheads (designated $E$ and $I$ ) and their extension to infinity in each direction.

Fan noise generally has an A-weighted spectrum with significant energy from $500 \mathrm{~Hz}$ to $4000 \mathrm{~Hz}$ and drop off at 250 and $8000 \mathrm{~Hz}$. Using the lowest significant frequency of $f=$ $500 \mathrm{~Hz}$ and the fundamental resonant frequency between two reflecting planes as guides, the images method proposed here is generally applicable for a distance $H$ greater than $H=$ $c / 2 f=0.35$ meters, where $c$ is the speed of sound. Since the fan sound power is expressed (and measured) as coming from the inlet only, and since it is treated as one lumped source, the images are single images.

The total acoustic intensity pressure squared incident on the openings of the plenum side wall which transforms to acoustic power flow through the openings is given as

$$
p_{w \text { total incident }}^{2}=p_{w \text { incident direct }}^{2}+p_{w \text { incident reverb }}^{2} .
$$

From the geometry in Figure 2, for the direct contribution, the incident pressure at the wall at an angle $\theta$ from the fan normal, including directivity $Q$, is given as

$$
\begin{aligned}
p_{\text {wall direct }}^{2} & =\frac{\rho c I I_{F} Q}{4 \pi\left[\left(H-H_{o}\right)^{2}+(0.5 W)^{2}\right]} \\
& =\frac{\rho c I I_{F}(\pi / 2) \cos \theta}{4 \pi\left[\left(H-H_{o}\right)^{2}+(0.5 W)^{2}\right]},
\end{aligned}
$$

where $\theta=\cot ^{-1}\left(\left(H-H_{o}\right) / 0.5 W\right), I I_{F}$ is the fan inlet power, and $\rho c$ is specific acoustic impedance of air.

The fan inlet power used in this analysis is the total inlet power measured by the AMCA procedure. The effects of any reflections from the solid portions of the side walls are included in a factor described later. 


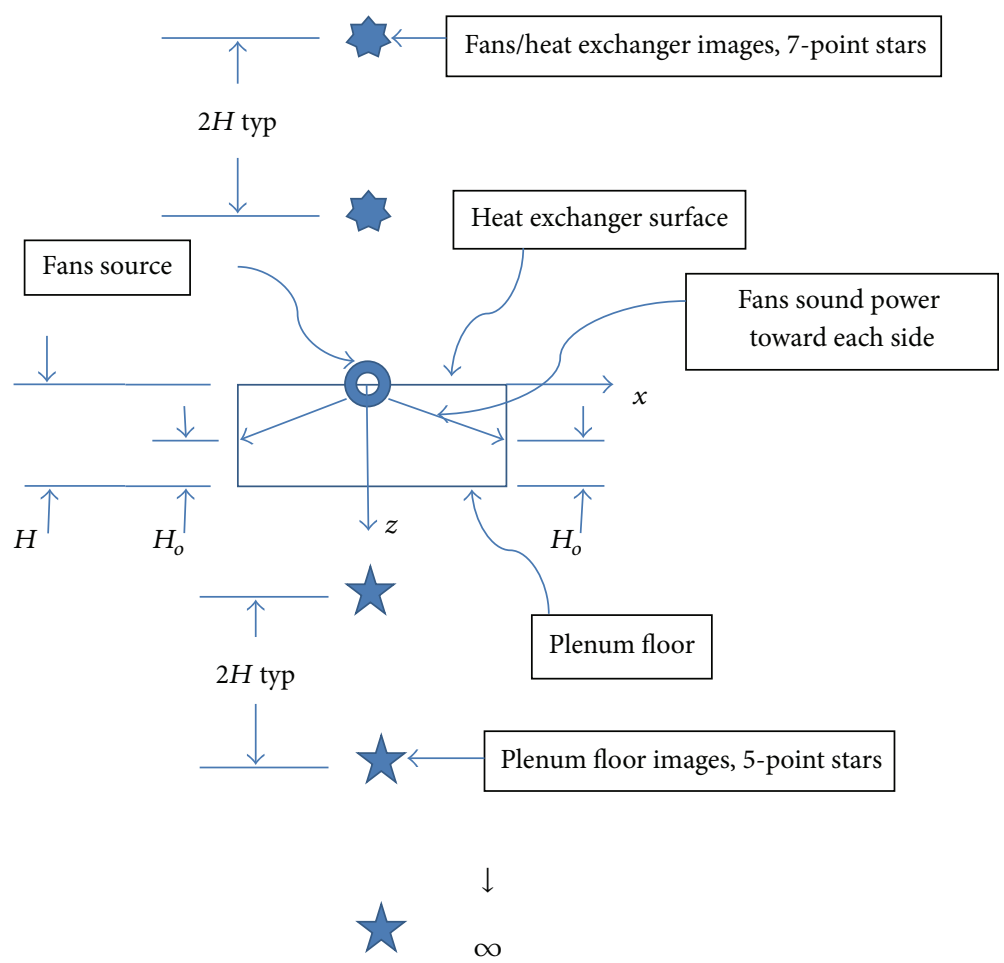

FIGURE 2: Plan view of the $x-z$ plane showing the multiple plenum floor and fans/radiator images of the fans point source at the top of the plenum. This is the first image group. Since the fans source is for the air inlet, each image is a single spherical source.

The intensity pressure incident at the wall is given by

$$
\begin{aligned}
p_{\text {incident direct }}^{2} & =p_{\text {incident direct }}^{2} \sin \theta \\
& =\frac{\rho c I I_{F}(\pi / 2) \cos \theta \sin \theta}{4 \pi\left[\left(H-H_{o}\right)^{2}+(0.5 W)^{2}\right]} .
\end{aligned}
$$

For the geometry in Figure 3, for the reverberant contribution, the distance from the $n m$ th image to the wall is given by the position vector

$$
\begin{aligned}
\text { Top Right: } \mathbf{R}_{n m}= & \left(\frac{W}{2}\right) \mathbf{i}-\left(\frac{m L}{2}\right) \mathbf{j} \\
& -\left(2 n H+\frac{H}{2}\right) \mathbf{k} \\
\text { Top Left: } \mathbf{R}_{n m}= & \left(\frac{W}{2}\right) \mathbf{i}+\left(\frac{m L}{2}\right) \mathbf{j} \\
& -\left(2 n H+\frac{H}{2}\right) \mathbf{k}
\end{aligned}
$$

Bottom Right: $\mathbf{R}_{n m}=\left(\frac{W}{2}\right) \mathbf{i}-\left(\frac{m L}{2}\right) \mathbf{j}$

$$
+\left(2 n H-\frac{H}{2}\right) \mathbf{k}
$$

$$
\text { Bottom Left: } \begin{aligned}
\mathbf{R}_{n m}= & \left(\frac{W}{2}\right) \mathbf{i}+\left(\frac{m L}{2}\right) \mathbf{j} \\
& +\left(2 n H-\frac{H}{2}\right) \mathbf{k},
\end{aligned}
$$

where $n$ represents the $n$th ceiling or floor image and $m$ represents the $m$ th left bulkhead or right bulkhead image.

The reverberant intensity incident on the wall is the dot product of the vector intensity and the unit vector in the $x$ direction normal to the wall.

For each image, $I_{R n m}$ is the intensity pressure magnitude, $\mathbf{I}_{\mathbf{R} n m}$ is the intensity vector, and $\mathbf{u}_{R n m}$ is the unit vector defining the direction of the intensity vector. The following gives the magnitude $I_{x R n m}$ of the intensity normal and incident to the wall:

$$
\begin{aligned}
& I_{R n m}=\frac{\rho c I I_{F}}{4 \pi R_{n m}^{2}} \\
& \mathbf{I}_{\mathbf{R} n m}=I_{n m} \mathbf{u}_{\mathbf{R} n m}=I_{n m}\left|\frac{\mathbf{R}_{n m}}{R_{n m}}\right| \\
& I_{R n m}=\mathbf{I}_{\mathbf{R} n m} \cdot \mathbf{i}=I_{n m}\left(\frac{x}{R_{n m}}\right)=\frac{\rho c I I_{F} x}{4 \pi R_{n m}^{3}} .
\end{aligned}
$$




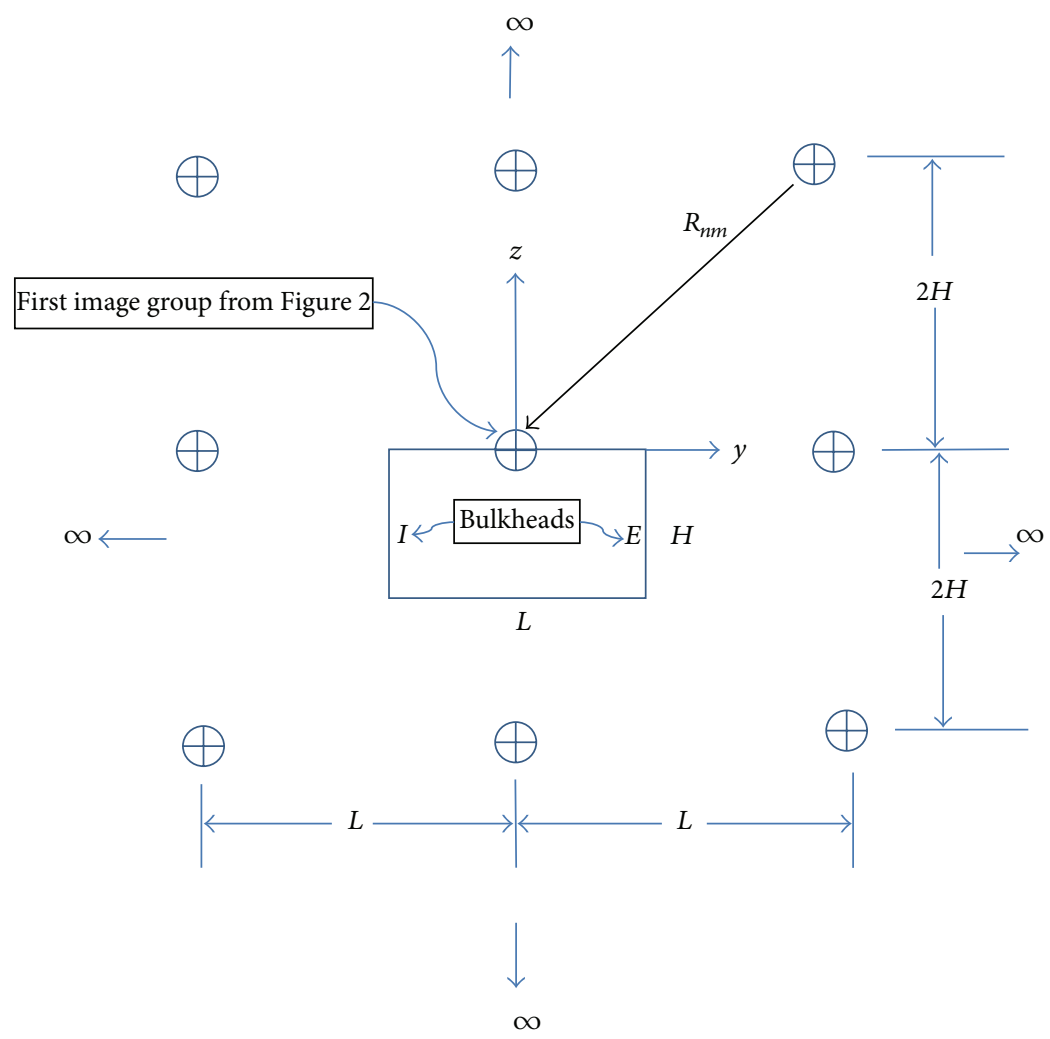

Figure 3: Elevation view of the $y-z$ plane showing the first image groups for the two plenum bulkheads (designated $E$ and $I$ ) and their extension to infinity in each direction.

At the wall, $x=W / 2$, the total reverberant incident pressure is given by

$$
\begin{aligned}
& p_{\text {incident reverb }}^{2}=\sum_{n=1}^{N} \sum_{m=0}^{M} I_{R n m}=\frac{\rho c I I_{F}}{4 \pi}\left(\frac{W}{2}\right) \\
& \cdot \sum_{n=1}^{N} \sum_{m=0}^{M}\left\{\frac{\left(1-\alpha_{\mathrm{HE}}\right)^{n}\left(1-\alpha_{R}\right)^{m}}{\left[(W / 2)^{2}+(m L / 2)^{2}+(2 n H+H / 2)^{2}\right]^{1.5}}\right. \\
& +\frac{\left(1-\alpha_{\mathrm{HE}}\right)^{n-1}\left(1-\alpha_{R}\right)^{m}}{\left[(W / 2)^{2}+(m L / 2)^{2}+(2 n H-H / 2)^{2}\right]^{1.5}} \\
& +\frac{\left(1-\alpha_{\mathrm{HE}}\right)^{n}\left(1-\alpha_{L}\right)^{m}}{\left[(W / 2)^{2}+(m L / 2)^{2}+(2 n H+H / 2)^{2}\right]^{1.5}} \\
& \left.+\frac{\left(1-\alpha_{\mathrm{HE}}\right)^{n-1}\left(1-\alpha_{L}\right)^{m}}{\left[(W / 2)^{2}+(m L / 2)^{2}+(2 n H-H / 2)^{2}\right]^{1.5}}\right\}
\end{aligned}
$$

where $\alpha_{\mathrm{HE}}$ is the random incidence sound coefficient of the heat exchanger, moving fan combination based on the amount of open area present there. $\alpha_{R}$ is the random incidence sound coefficient of the bulkhead toward the rear of the plenum. $\alpha_{L}$ is the random incidence sound coefficient of the bulkhead toward the interior of the plenum.
To account for the multiple reflections from the solid portion of the side walls that contain the large air inlet openings, a reverberant factor $F$ is given by

$$
F=1+\frac{1}{2} \sum_{m=1}^{M}\left(1-\alpha_{w, \text { ave }}\right)^{2 m} \quad \alpha_{w, \text { ave }}=\frac{\left(\alpha_{w} A_{s}+A_{o}\right)}{(L H)}
$$

where $\alpha_{w \text {,ave }}$ is the net random incidence sound coefficient of the side wall including opening and solid wall areas.

For all calculations, the condition of hard untreated surfaces uses a $\alpha_{\text {hard }}=0$ value. Thus, the image model does not require any $\alpha_{\text {hard }}$ value estimate which is very difficult to determine but crucial for a large room type enclosure model. This is one of the advantages of the image method used here. The total reverberant incident pressure is then given by the product of (6) and $F$ from (7).

\section{Noise Radiated to Wayside Position}

The total incident pressure squared $p_{w}^{2}$ from the sum of (3) and ((6), (7)) is transmitted through the plenum wall openings with a field incidence sound transmission loss value of $\mathrm{TL}_{o} \mathrm{dBA}$ for any acoustic louver or silencer at the openings. $\mathrm{TL}_{o}$ is given as a weighted average based on the fan frequency spectrum. The sound power radiated by the plenum wall openings of area $A_{o}$ to the wayside is given by

$$
I I_{\text {openings }}=\frac{\tau_{0} p_{w}^{2} A_{o}}{\rho c} \quad \tau_{o}=10^{-\mathrm{TL}_{o} / 10} .
$$


Hohenwarter's [11] method of calculating noise radiation from a plane rectangular surface is used to determine the wayside level at a distance of $z$ from the surface where $z$ is the distance from plenum centerline minus one-half the width of the plenum. Considering a perfectly reflecting ground, the pressure squared at the wayside is given by

$$
p_{\text {wayside }}^{2}=\frac{4 \rho c I I_{\text {openings }}}{\pi H W} \tan ^{-1}\left(\frac{H W}{2 z \sqrt{4 z^{2}+W^{2}}+H^{2}}\right) .
$$

In terms of the sound power level (PWL) of the wall and distances measured in meters, the sound pressure level at wayside due to the fan inlet is given by

$$
\begin{aligned}
& \mathrm{SPL}_{\text {wayside inlet }} \\
& =\mathrm{PWL}_{\text {openings }}-\mathrm{TL}_{o}+1.2-10 * \log _{10}(W H) \\
& \quad+10 * \log _{10}\left[\tan ^{-1}\left(\frac{H W}{2 z \sqrt{4 z^{2}+W^{2}}+H^{2}}\right)\right] .
\end{aligned}
$$

In terms of the sound power level (PWL) of the fan inlet and distances measured in meters, the sound pressure level at wayside is given by

$$
\begin{aligned}
& \mathrm{SPL}_{\text {wayside inlet }} \\
& =\mathrm{PWL}_{\text {fan inlet }}+10 * \log _{10}(\mathrm{DR})-\mathrm{TL}_{o}+1.2+10 \\
& \quad * \log _{10}\left[\tan ^{-1}\left(\frac{H W}{2 z \sqrt{4 z^{2}+W^{2}}+H^{2}}\right)\right],
\end{aligned}
$$

where DR $=p_{w \text { total incident }}^{2} / \rho c I I_{F}$ from (3), (6), and (7).

The wayside sound pressure level due to the fan exhaust sound power level (which is typically given as the same value as the inlet level in (11)) is given by

$$
\begin{aligned}
\mathrm{SPL}_{\text {wayside exhaust }}= & \mathrm{PWL}_{\text {rad fan exhaust }}-\mathrm{DI}-\mathrm{TLE}-20 \\
& * \log _{10}\left(r_{w} * 3.28\right)+2.5
\end{aligned}
$$

where DI is the exhaust directivity index at 90 degrees. TLE is the transmission loss of any exhaust silencing device. $r_{w}$ is the distance (meters) from the plenum centerline.

The total wayside level is given by the combination of (11) and (12):

$$
\begin{aligned}
& \mathrm{SPL}_{\text {wayside }}=10 * \log _{10}\left[10^{(\mathrm{SPL} \text { wayside inlet } / 10)}\right. \\
& \left.+10^{(\mathrm{SPL} \text { wayside exhaust } / 10)}\right]
\end{aligned}
$$

\section{Numerical Example and Experimental Results}

The method is applied to an isolated radiator cab plenum of a large locomotive containing axial fans at the top. The plenum dimensions and model parameters are given as follows:

$$
\begin{aligned}
& L=2.59 \mathrm{~m} \text {, plenum length. } \\
& W=1.93 \mathrm{~m} \text {, plenum width. }
\end{aligned}
$$

$H=2.06 \mathrm{~m}$, plenum height.

$A_{s}=1.06 \mathrm{~m}^{2}$, the solid area at the side.

$A_{o}=3.66 \mathrm{~m}^{2}$, the open area at the side (this represents $69 \%$ open area per side of plenum).

$H_{o}=1.43 \mathrm{~m}$, height of center of openings.

$\mathrm{TLE}=0$, fan exhaust silencer dBA loss.

$\mathrm{TL}_{o}=0$, air inlet opening.

$N=15$, number of floor ceiling images.

$M=40$, number of side wall images.

$\mathrm{PWL}=120 \mathrm{dBA}$ fan sound power level as determined from AMCA test.

$r_{w}=7.5 \mathrm{~m}$, wayside distance to plenum centerline.

$z=r_{w}-W / 2=6.64 \mathrm{~m}$, wayside distance to side of plenum.

$\alpha_{R}=\alpha_{L}=\alpha_{\mathrm{HE}}=\alpha_{w}=\alpha_{\text {hard }}=\alpha_{c}=0$.

$\alpha_{w \text {,ave }}=0.69$, overall average absorption coefficient of the entire side wall.

In a plenum of this type with large side openings and axial fans located at the top, the wayside sound pressure level is dominated by the sound radiated through the side air inlet openings. The sound radiated from the fan exhaust to the wayside is substantially less due to the ninety-degree directivity of the vertical fan exhaust relative to the wayside. However, since a wayside measurement includes both side inlet and top exhaust contributions, the top area directivity index DI requires consideration for the model. In the sense of overall dBA level, the top radiation area is represented as a randomly vibrating area of diameter $b$ and correlation distance $w_{c}$. Using the analysis from Morse and Ingard [12], the directivity index as a function of angle $\theta$ and wave number $k=2 \pi f / c$ is given as

$$
\begin{gathered}
\mathrm{DI}(\theta)=\log _{10}\left[\frac{p^{2}(\theta)}{(2 / \pi) \int_{0}^{\pi / 2} p^{2}(\theta) d \theta}\right], \\
p^{2}(\theta)=\frac{\rho c I I_{F}}{2 \pi r^{2}} \frac{\left(k w_{c}\right)^{2}}{\left[1+\left(k w_{c}\right)^{2} \sin ^{2}(\theta)\right]^{3 / 2}} .
\end{gathered}
$$

Figure 4 gives the directivity index $(\mathrm{dB})$ at $\theta=90^{\circ}$ as a function of frequency $f$ as an average over the range of correlation distance $w_{c}=b / 4$ to $w_{c}=b / 2$.

An A-weighted directivity index is determined from a weighted average using the fan PWL spectrum as the weighting factor. Table 2 gives the fan octave band A-weighted spectrum.

The formula for A-weighted directivity index is given as

$$
\begin{aligned}
\mathrm{DI} & =\mathrm{PWL}_{\text {overall }}-10 \log _{10}\left[\sum_{n=1}^{5} 10^{\left(\operatorname{PWL}\left(f_{i}\right)-\mathrm{DI}\left(f_{i}\right)\right) / 10}\right] \\
& =11 \mathrm{dBA} .
\end{aligned}
$$




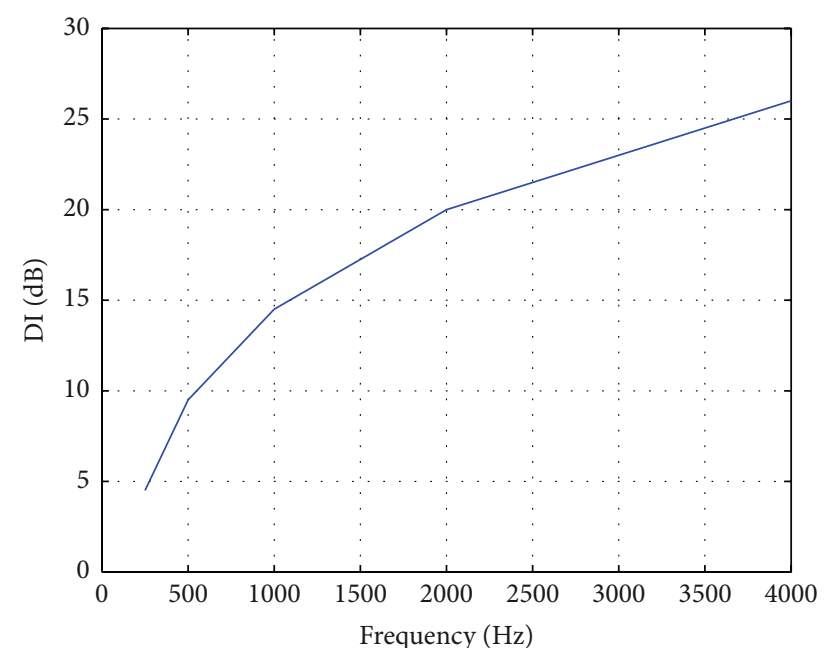

FIGURE 4: Directivity index from fan exhaust at the top of plenum.

TABLE 2: Fan octave band spectrum.

TABLE 3: Experimental results.

\begin{tabular}{lccr}
\hline & Run \# 1 & Run \# 2 & Run \# 3 \\
\hline 30 second $L_{\text {eq }}$ & $93.3 \mathrm{dBA}$ & $93.1 \mathrm{dBA}$ & $93.3 \mathrm{dBA}$ \\
$L_{\max }$ over 30 seconds & $93.7 \mathrm{dBA}$ & $93.4 \mathrm{dBA}$ & $93.7 \mathrm{dBA}$ \\
\hline
\end{tabular}

The model presented here gives the following results:

$$
\begin{gathered}
\left\{\begin{array}{l}
\text { SPL_wayside_inlet }=93.2 \mathrm{dBA} \\
\text { SPL_wayside_exhaust }=83.7 \mathrm{dBA}
\end{array}\right. \\
\longrightarrow \text { SPL_wayside }=93.7 \mathrm{dBA} .
\end{gathered}
$$

Experimental values were obtained outdoors in an area where large reflecting surfaces were far enough away to prevent any effect. A hard ground surface existed between the plenum and the measurement location. Data taken at the location used in the model and $1.6 \mathrm{~m}$ from the ground is summarized in Table 3. Each measurement was recorded for 30 seconds using an integrating type 1 sound level meter set on A-scale. With the fan operating at its steady state condition, the sound pressure level was very consistent over the time interval.

The comparison is encouraging giving less than $0.5 \mathrm{dBA}$ difference between model and experiment.

\section{Comparison with Diffused Field Enclosure Model}

The large room diffuse field reverberant model (Sabine model) for an enclosure follows the common result as given in Embleton [13]. We define the following parameters:

$$
S=\text { total internal surface area. }
$$

$S_{a}=$ total internal surface area of sound absorption material.

$S_{o}=$ total surface area of wall air inlet openings.

$\alpha_{h}=$ Sabine sound absorption coefficient of hard internal surfaces.

$\alpha_{a}=$ Sabine sound absorption coefficient of sound absorption material.

$\alpha_{\mathrm{Sab}}=$ Sabine sound absorption coefficient of enclosure interior.

$P_{W}, P_{F}$, and $P_{C}=$ percent of sound absorption coverage on walls, floor, and ceiling, respectively.

$I I_{F}=$ sound power of fan noise source.

The total sound intensity $p_{\text {incident }}^{2}$ incident on side wall openings includes the direct contribution from air inlet opening to wall opening and the diffuse field reverberant contribution.

The following relationships apply to the acoustic environment from the sound power output of the noise source to the sound intensity incident on the side wall openings:

$$
\begin{aligned}
S= & 2(W L+L H+W H) \\
S_{a}= & 2\left(\frac{P_{W}}{100}\right)\left(\left(L H-S_{o}\right)+W H\right) \\
& +\left(\frac{P_{C}}{100}\right) W L+\left(\frac{P_{F}}{100}\right) W L \\
\alpha_{\text {Sab }}= & \frac{S_{a} \alpha_{a}+\alpha_{h}\left(S-S_{a}-2 S_{o}\right)+2 S_{o}}{S} \\
p_{\text {incident reverb }}^{2}= & \rho c I I_{F}\left(\frac{1}{\alpha_{\text {Sab } S}}\right) .
\end{aligned}
$$

Using (3) for $p_{\text {incident direct }}^{2}$ and the Hohenwarter radiation model from $((9)-(13))$, the numerical example gives

$$
\begin{aligned}
& \text { SPL_wayside }=97.3 \mathrm{dBA} \text { for } \alpha_{a}=0 \text { and } \alpha_{h}=0, \\
& \text { SPL_wayside }=96.9 \mathrm{dBA} \text { for } \alpha_{a}=0 \text { and } \alpha_{h}=0.05, \\
& \text { SPL_wayside }=96.5 \mathrm{dBA} \text { for } \alpha_{a}=0 \text { and } \alpha_{h}=0.1,
\end{aligned}
$$

which are approximately 3-4 dBA higher than the image model and the experimental results.

Thus, the large room diffuse model significantly overestimates the amount of enclosure reverberation relative to the direct noise from fan source to opening. When a 0.8 sound absorption coefficient material is added to $100 \%$ of the end wall surfaces, $100 \%$ of the ceiling surface, and $100 \%$ of the solid side wall surfaces, the models give the following results:

Large room diffuse field model: SPL_wayside $=$ 94.3 dBA for $\alpha_{a}=0.8$ and $\alpha_{h}=0$ (3.0 dBA noise reduction).

Image based model: SPL_wayside $=92.4 \mathrm{dBA}$ for $\alpha_{R}=$ $\alpha_{L}=\alpha_{w}=\alpha_{c}=0.8$ and $\alpha_{h}=0$ (1.3 dBA noise reduction). 
The image model gives less than half the noise reduction of the diffuse model via a change from no absorption to a maximum amount of absorption material on the internal plenum surfaces. This indicates that a standard diffuse enclosure model for this special case of a plenum enclosure with large open sides overestimates the plenum reverberation relative to the image model presented in this paper.

\section{Conclusions}

Application of the mathematical images group concept presented here provides a means of estimating the sound reverberation inside a special fan plenum sound enclosure with mostly open sides where the primary noise sources are the air inlets of axial type fans located at the top of the enclosure. The paper contributions include novel ways for mathematically representing the images groups first introduced for a tight-fitting enclosure [10]. The reverberation estimate is performed with zero sound absorption coefficient for all hard surfaces and without having to estimate or measure the initial hard wall sound absorption. The model considers how the main reverberant part defined between the parallel surfaces of plenum floor and fans/heat exchanger ceiling is amplified by a double summation of images from two parallel bulkheads' reflections, its images from combined bulkheads, floor/ceiling reflections, and a unique factor accounting for possible multiple reflections from the acoustically hard surfaces of the side wall frame members. The use of zero sound absorption for the initial hard surface case precludes having to apply an educated but quite possibly an inaccurate estimate or actual measurement of the hard surfaces condition. The model considers fan directivity based on random area source, provides an estimate of the sound transmission through the large side air inlet openings, and the radiation to wayside positions using a Hohenwarter radiation surface. The contribution of the air inlets combined with the contribution of the fan exhaust and the total sound level at a wayside position is compared with experimental results. The experimental results show that the images group model presented for this case is very accurate and provides a much better prediction than that for a standard large room diffuse field model. This may also be viewed as a good verification of a group images model concept for other special cases of enclosure geometry and source orientation such as that previously presented for a tight-fitting enclosure.

\section{Conflict of Interests}

The author declares that there is no conflict of interests regarding the publication of this paper.

\section{References}

[1] H.-J. Kim and J.-G. Ih, "Acoustic performance of the lined rectangular plenum chamber," in Proceedings of the Inter-Noise 2003, pp. 1312-1319, Seogwipo, Republic of Korea, August 2003.

[2] T. A. Osman, "Design charts for the selection of acoustical enclosures for diesel engine generator sets," Proceedings of the Institution of Mechanical Engineers Part A: Journal of Power and Energy, vol. 217, no. 3, pp. 329-336, 2003.
[3] F. Forouharmajd and P. Nassiri, "The investigation of plenum chamber role in noise reduction of a fan and air ducts," in Proceedings of the 39th International Congress on Noise Control Engineering (INTER-NOISE '10), pp. 33-40, Lisbon, Portugal, June 2010.

[4] H. G. Davies, "Noise propagation in corridors," Journal of the Acoustical Society of America, vol. 53, no. 5, pp. 1253-1262, 1973.

[5] S. H. Chu and S. K. Tang, "Theory and three-dimensional numerical simulation of sound propagation along a long enclosure with side opening," in Proceedings of the 43rd International Congress on Noise Control Engineering (INTER.NOISE '14), pp. 246-253, Melbourne, Australia, November 2014.

[6] T. Yamamoto, "On the distribution of sound in a corridor," Journal of the Acoustical Society of Japan, vol. 17, pp. 286-292, 1961.

[7] T. L. Redmore, "A theoretical analysis and experimental study of the behaviour of sound in corridors," Applied Acoustics, vol. 15, no. 3, pp. 161-170, 1982.

[8] J. Kang, "Reverberation in rectangular long enclosures with geometrically reflecting boundaries," Acustica, vol. 82, no. 3, pp. 509-516, 1996.

[9] D. A. Bies and C. H. Hansen, "Sound in enclosed spaces", in Engineering Noise Control, chapter 7, E \& FN Spon, 1996.

[10] M. J. Panza, "A mathematical images group model to estimate the sound level in a close-fitting enclosure," Advances in Acoustics and Vibration, vol. 2014, Article ID 284362, 7 pages, 2014.

[11] D. Hohenwarter, "Noise radiation of (rectangular) plane sources," Applied Acoustics, vol. 33, no. 1, pp. 45-62, 1991.

[12] P. M. Morse and K. U. Ingard, "Theoretical acoustics," in The Radiation of Sound, chapter 7, McGraw-Hill, 1968.

[13] T. F. Embleton, "Sound in large rooms," in Noise and Vibration Control, L. L. Beranek, Ed., chapter 9, McGraw-Hill, New York, NY, USA, 1971. 

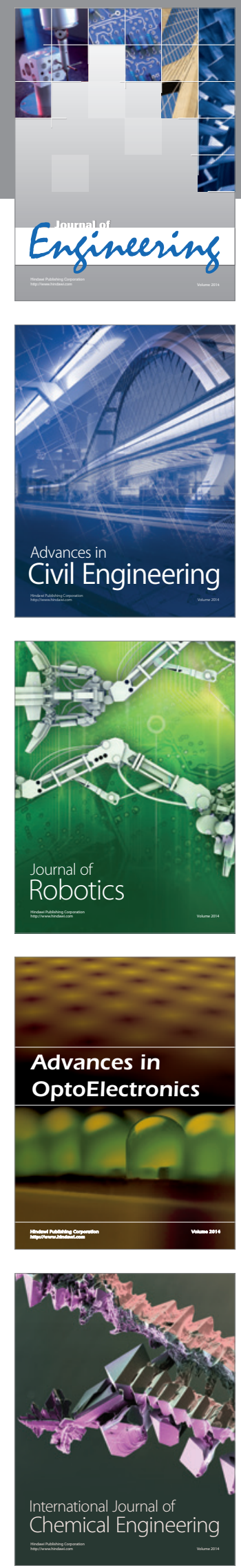

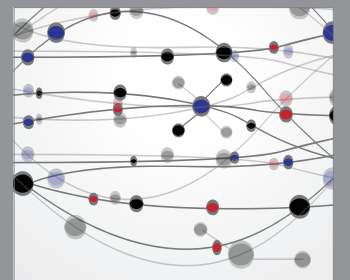

The Scientific World Journal
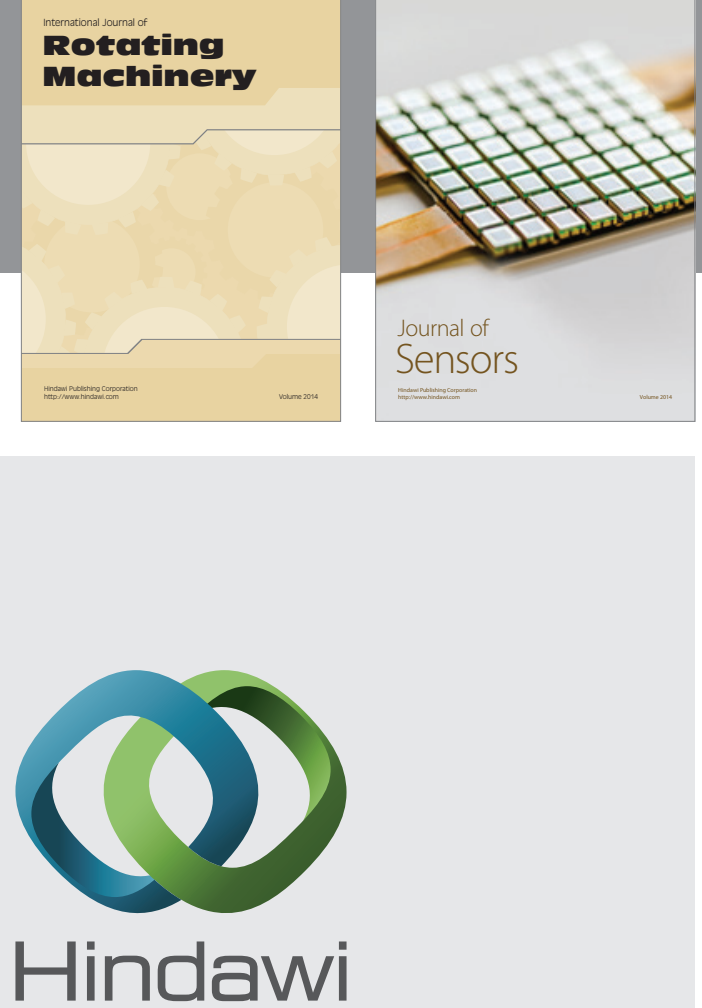

Submit your manuscripts at http://www.hindawi.com
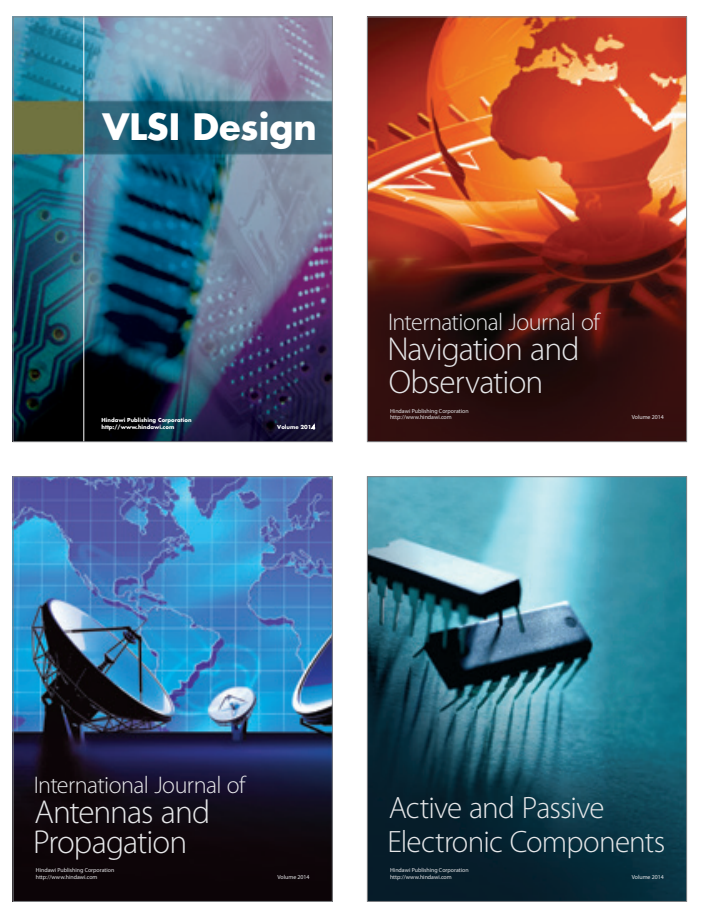
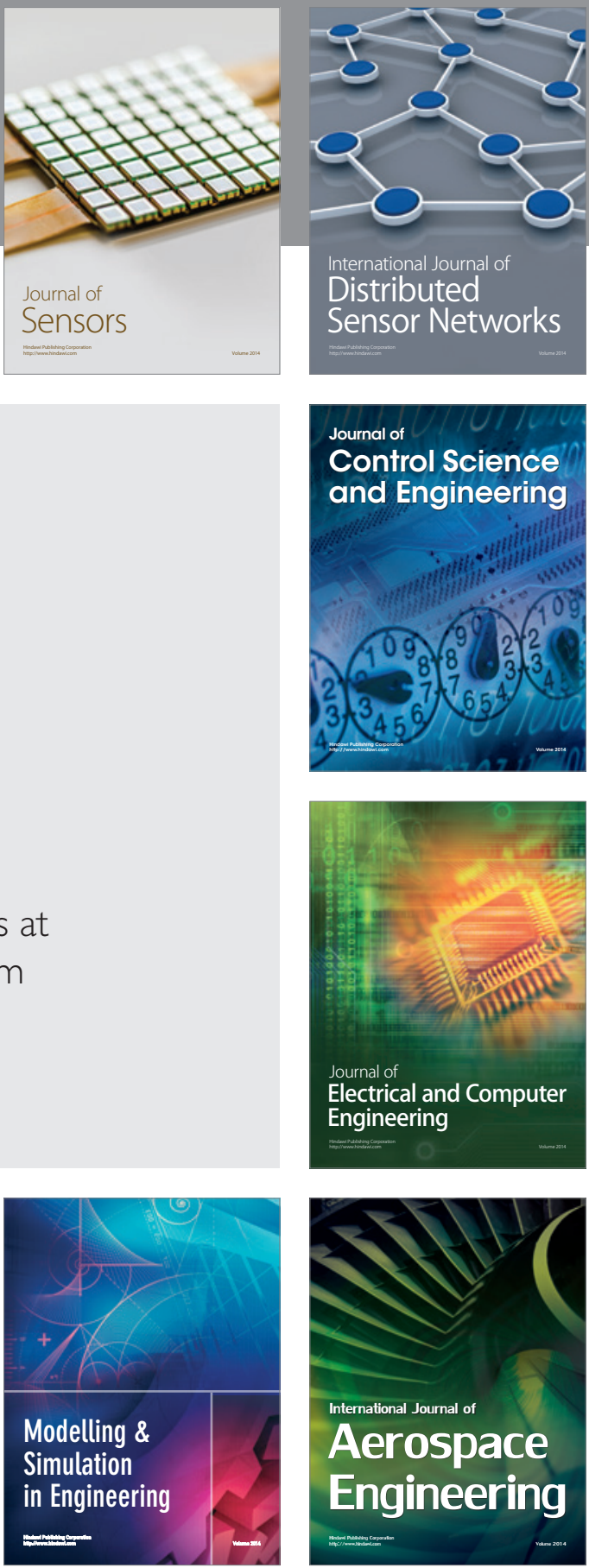

Journal of

Control Science

and Engineering
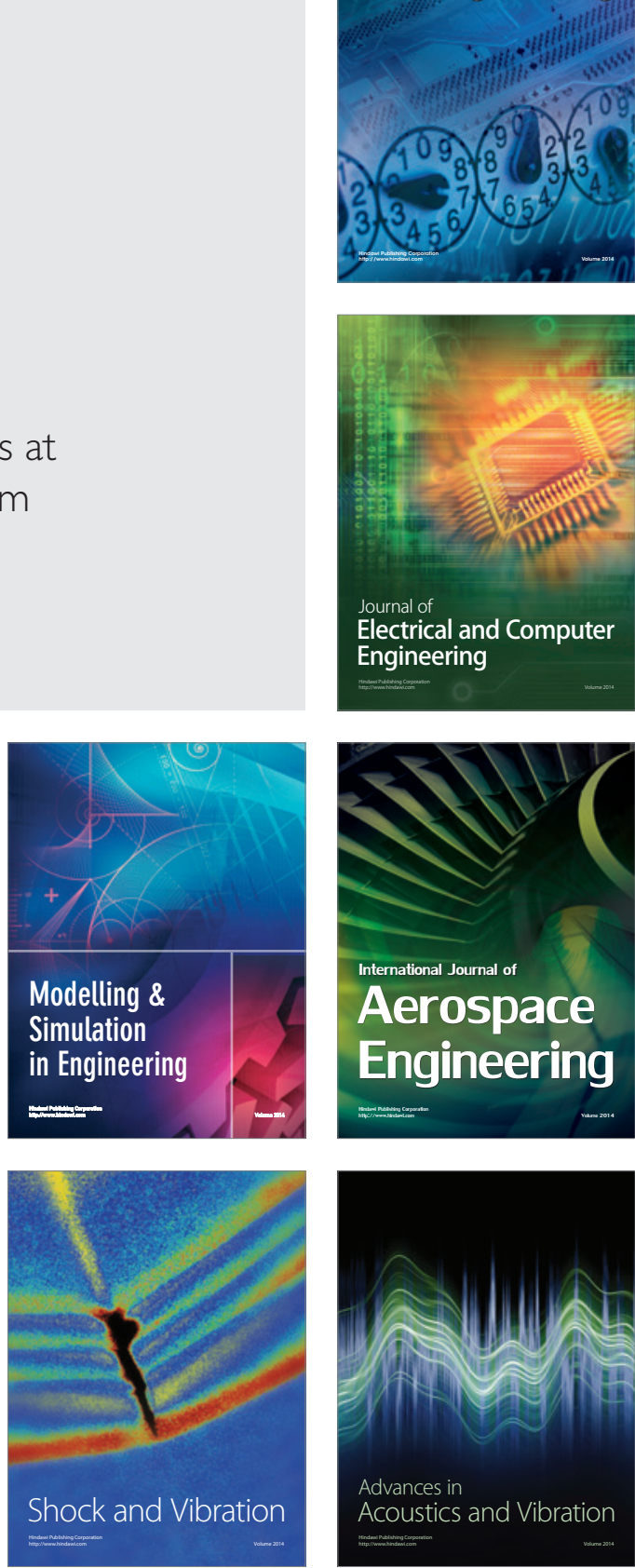